\title{
Histomorphometric Analysis of Umbilical Arteries in Preeclampsia
}

\author{
Saleena N Ali', Suma H Y', Yogesh Ashok Sontakke ${ }^{3}$, Dilip Kumar Maurya ${ }^{4}$ \\ ${ }^{1}$ Assistant Professor, Department of Anatomy, P K Das Institute of Medical Sciences, ${ }^{2}$ Additional Professor, Department of Anatomy, JIPMER, ${ }^{3}$ Associate \\ Professor, Department of Anatomy, JIPMER, ${ }^{4}$ Additional Professor, Department of Obstetrics and Gynaecology, JIPMER
}

\section{Abstract}

Introduction: Preeclampsia is a pregnancy-related hypertensive disorder complicated with placental hypoxia and resistance. The hypoxia and hypertension can induce changes in the morphometric parameters of umbilical cord and its vessels that can further affect the blood flow to the fetus. Subjects and Methods: Umbilical cords were collected from new-borns of preeclamptic and normal mothers, length and diameter were measured. Further, cords were processed for histological examination. The diameter, luminal area and wall thickness of umbilical arteries were measured. Results: A shorter and narrower cord was observed in preeclampsia. The umbilical arteries in preeclamptic cases were dilated, whereas statistically significant changes were not observed in the thickness of wall. Conclusion: Dilated umbilical arteries would be an adaptation to the affected babies so as to ensure reduced resistance for fetal circulation.

Keywords: Preeclampsia, Umbilical artery, Luminal area, Diameter

Corresponding Author: Dr. Suma H Y, Additional Professor, Department of Anatomy, Jawaharlal Institute of Postgraduate Medical Education and Research (JIPMER), Puducherry.

Received: February 2019

Accepted: March 2019

\section{Introduction}

Preeclampsia is a pregnancy-related hypertensive disorder that has the potential to affect any organ system in the body. Preeclampsia accounts for $2 \%-8 \%$ of all pregnancies ${ }^{[1]}$ with a maternal mortality rate reported as $6.81 \%{ }^{[2]}$ The key mechanism underlying the development of preeclampsia is thought to be abnormal placentation owing to defective invasion of the spiral arteries. It leads to several consequences such as placental hypoxia and endothelial dysfunction that further lead to intrauterine growth retardation, acidosis and high risk of prematurity. ${ }^{[3-5]}$

The umbilical cord ties the fetus with the maternal placenta. It consists of a single vein and two arteries embedded in a loose connective tissue, the Wharton's jelly. The umbilical arteries carry deoxygenated blood from the fetus to the chorionic villi of placenta for oxygenation. These vessels are sensitive to the hemodynamic changes in preeclampsia since they are not supplied by vasa vasorum and depend on their own oxygen supply. Hence, hypoxia and hypertension can induce deviations in the histomorphometry of the umbilical vessels. A reduction, ${ }^{[6,7]}$ as well as, augmentation of the arterial lumen has been reported in literature. ${ }^{[8,9]}$ The change in calibre as well as the structure of the vessels can influence the rate of blood flow and in turn, the fetal circulation. Hence, the present study was carried out to evaluate the morphological changes in the umbilical arteries by histological examinations.

\section{Subjects and Methods}

The study was conducted as a cross-sectional analytical study with two groups. Group 1 included patients who were diagnosed with preeclampsia $(n=49)$ and group 2 included healthy, normal, pregnant females $(n=49)$. Patients with chronic hypertension, gestational diabetes mellitus and cardiovascular diseases were excluded from the study. The length of the cord was measured using a measuring tape and diameter by Vernier callipers. The study was approved by the institute's research and ethical committee.

Umbilical cords were collected from new-borns of women delivered in a tertiary care hospital during the period 2016 to 2018 after availing a written informed consent from the mothers recruited to the study. Cord samples were collected from the placental and fetal ends of the cord $(1 \mathrm{~cm}$ from the respective attachments). The tissues were fixed in $10 \%$ neutral buffered formalin and further processed with grades of alcohol (dehydration), xylene (clearing) and paraffin (impregnation and embedding). Sections of $5 \mu \mathrm{m}$ thickness were cut using a microtome and further stained using haematoxylin and eosin. ${ }^{[10]}$ After mounting, slides were viewed using Olympus BX43 bright field microscope.

The diameter of the lumen, the luminal area of the artery, and the total wall thickness were measured using ImageJ software. The total wall thickness was measured from the endothelium to the last row of smooth muscle cells in tunica media. All the data were analyzed using SPSS software 
(version 19.0). The data were expressed as mean $\pm \mathrm{SD}$ or median (Interquartile range (IQR)) as per the distribution of data and tested using Independent t-test or Mann Whitney-U test accordingly. A p-value less than 0.05 was considered as statistically significant.

\section{Result}

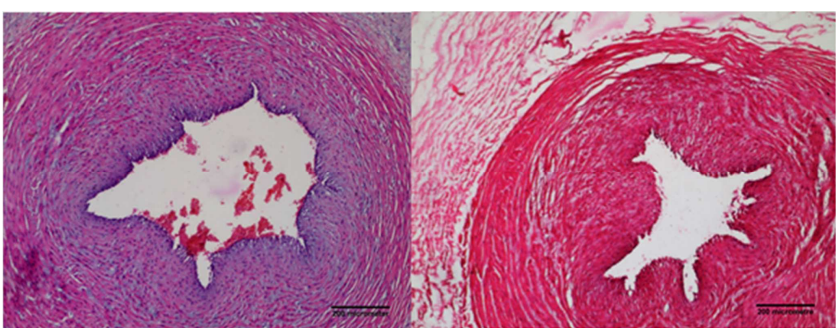

Figure 1: Dilated umbilical artery in group 1 (preeclampsia) (X100)

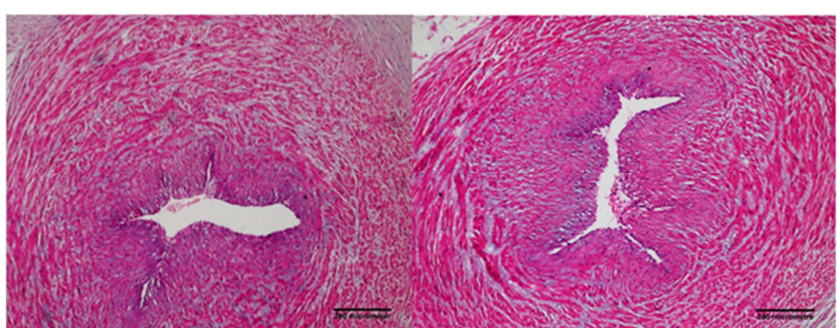

Figure 2: Umbilical artery in group 2 (control samples) (X100)

Table 1: Morphometry of umbilical cord and arteries in preeclampsia and control samples

\begin{tabular}{|c|c|c|c|}
\hline Parameter & $\begin{array}{l}\text { Preeclampsia } \\
(n=49) \\
\text { Mean } \pm \text { SD/ } \\
\text { median }(I Q R)\end{array}$ & $\begin{array}{l}\text { Control }(n \\
=49) \\
\text { Mean } \pm \mathrm{SD} / \\
\text { median } \\
(\mathrm{IQR})\end{array}$ & $\begin{array}{l}\text { p- } \\
\text { value }\end{array}$ \\
\hline $\begin{array}{l}\text { Length of the cord } \\
(\mathrm{cm})\end{array}$ & $37.76 \pm 4.91$ & $50.05 \pm 4.84$ & $<0.001$ \\
\hline $\begin{array}{l}\text { Diameter of the cord } \\
\text { at placental end } \\
(\mathrm{mm})\end{array}$ & 7.89 (1.94) & $10.24(1.45)$ & $<0.001$ \\
\hline $\begin{array}{l}\text { Diameter of the cord } \\
\text { at fetal end }(\mathrm{mm})\end{array}$ & $8.34 \pm 1.48$ & $9.83 \pm 1.51$ & $<0.001$ \\
\hline $\begin{array}{l}\text { Diameter of } \\
\text { umbilical artery at } \\
\text { placental end }(\mathrm{mm})\end{array}$ & $0.51(0.22)$ & $0.36(0.23)$ & 0.005 \\
\hline $\begin{array}{l}\text { Diameter of the } \\
\text { umbilical artery at } \\
\text { fetal end }(\mathrm{mm})\end{array}$ & $0.51 \pm 0.14$ & $0.31 \pm 0.11$ & $<0.001$ \\
\hline $\begin{array}{l}\text { Luminal area of the } \\
\text { artery at placental } \\
\text { end }(\mathrm{mm} 2)\end{array}$ & $1.12(1.67)$ & $0.77(0.73)$ & $<0.001$ \\
\hline $\begin{array}{l}\text { Luminal area of the } \\
\text { artery at fetal end } \\
(\mathrm{mm} 2)\end{array}$ & $0.75(1.08)$ & $0.43(0.39)$ & $<0.001$ \\
\hline $\begin{array}{l}\text { Wall thickness of } \\
\text { artery at placental } \\
\text { end }(\mu \mathrm{m})\end{array}$ & $511.9(103)$ & $524.0(23)$ & 0.150 \\
\hline $\begin{array}{l}\text { Wall thickness of } \\
\text { artery at fetal end } \\
(\mu \mathrm{m})\end{array}$ & $532.3(61.9)$ & $554.5(72.6)$ & 0.054 \\
\hline
\end{tabular}

The mean age of both groups was 25 years. The gestational age was lower in preeclampsia with $55.1 \%$ cases being less than 37 weeks. In group 2, all the subjects had a gestational age above 37 weeks. The morphometric parameters of the cord such as length of the cord, diameter of the cord at placental and fetal ends were measured. The umbilical cords were significantly shorter and narrower in preeclampsia. The luminal diameter, area, wall thickness were measured from histological slides. The luminal area of umbilical arteries was significantly increased in preeclampsia [Figure 1] compared to group 2 [Figure 2]. However, a statistically significant difference in the wall thickness was not observed between the two groups. [Table 1] shows the histomorphometric parameters of the cord and umbilical arteries.

\section{Discussion}

The gestational age was comparatively lower in preeclampsia as compared to group 2. This could be explained by the fact that early medical interventions are needed in preeclampsia and thus, termination of pregnancy might be required. The umbilical cords affected by preeclampsia were found to be significantly shorter and narrower at both ends compared to the control group. The present findings are consistent with the results of Koech et al. (2008) and Yasoob et al. (2014) who found a decrease in the length of the cord in preeclampsia. ${ }^{[1,12]}$ The reduction in length was attributed to a deficiency of ghrelin, a potent growth factor, resulting in reduced blood flow and nutrients to the cord. ${ }^{[12]}$ A lower gestational age also might be a causative factor for a shorter cord. The reduction in the diameter, as well as the cross-sectional area, has been ascribed to the reduction in the Wharton's jelly. Hyaluronic acid, the main constituent of the glycosaminoglycans, is replaced by sulfated proteoglycans, thus, resulting in reduced Wharton's jelly content as well as hydration in preeclampsia. ${ }^{[8]}$ A reduction in the volume of the jelly would, in turn, lead to altered hemodynamics that further result in compromised blood flow and intrauterine growth retardation. ${ }^{[13]}$

Blanco et al. (2010) reported a wider arterial lumen in umbilical cords of preeclamptic patients that was attributed to the decreased responsiveness of smooth muscle cells to a high stretch. ${ }^{[9]}$ Similar to the previous study, a significant increase in the diameter and luminal area of the umbilical artery at the placental and fetal ends was observed in the present study. In contrast to the present study, Inan et al. (2002) and Jain et al. (2016), demonstrated a reduced luminal area and wall thickness in preeclampsia owing to vasoconstriction and hypoplasia. ${ }^{[6,8]}$ On the contrary, Almasry et al. (2016) described a thicker arterial wall concomitant with a narrow lumen as a result of proliferation of smooth muscle cells. ${ }^{[14]}$ It has been assumed that the modifications in these histomorphometric parameters could be the result of placental hypoxia, a key pathological factor in preeclampsia. ${ }^{[8]}$ The consequences of diminished oxygen tension on various blood vessels have been studied earlier. Except for the pulmonary vessels, all other systemic vessels responded to hypoxia with an initial vasoconstriction followed by vasodilatation. ${ }^{[15-17]}$ Thus, we hypothesize that the dilated lumen of the umbilical arteries could be a 
secondary response to placental hypoxia in preeclampsia. Fetal vascular malperfusion (also known as fetal thrombotic vasculopathy) is a complication associated with various pregnancy-related disorders, such as preeclampsia, lupus anticoagulant and so on, characterized by venous congestion. Multiple pathological factors that involve the entire vascular tree from the umbilical vessels to the stem villi in the chorionic plate contribute to the development of fetal vascular malperfusion, the most common being obstruction of the umbilical cord. ${ }^{[18,19]}$ Hence, dilated umbilical arteries could be an adaptation for affected babies to ensure better venous drainage.

\section{Conclusion}

Dilated umbilical arteries would be an adaptation to the affected babies so as to ensure reduced resistance for fetal circulation.

\section{References}

1. Khan KS, Wojdyla D, Say L, Gülmezoglu AM, Van Look PF. WHO analysis of causes of maternal death: a systematic review. Lancet. 2006;367(9516):1066-74.

2. Berg CJ, Callaghan WM, Syverson C, Henderson Z. Pregnancyrelated mortality in the United States, 1998 to 2005. Obstet Gynecol. 2010;116(6):1302-9.

3. Steegers EA, von Dadelszen P, Duvekot JJ, Pijnenborg R. Preeclampsia. Lancet. 2010(9741);376:631-44.

4. von Dadelszen P, Magee LA, Roberts JM. Subclassification of preeclampsia. Hypertens Pregnancy. 2003;22(2):143-8.

5. Uzan J, Carbonnel M, Piconne O, Asmar R, Ayoubi JM. Preeclampsia: pathophysiology, diagnosis, and management. Vasc Health Risk Manag. 2011;7:467-74.

6. Inan S, Sanci M, Can D, Vatansever S, Oztekin O, Tinar S. Comparative morphological differences between umbilical cords from chronic hypertensive and preeclamptic pregnancies. Acta
Med Okayama. 2002;56(4):177-86.

7. Raio L, Ghezzi F, Di Naro E, Duwe DG, Cromi A, Schneider H. Umbilical cord morphologic characteristics and umbilical artery Doppler parameters in intrauterine growth-restricted fetuses. J Ultrasound Med. 2003;22(12):1341-7.

8. Jain A, Sharma V, Baweja S, Sharma D, Jain R. Comparative histomophometric differences between umbilical cords from normal and pre-eclamptic pregnancies. $\mathrm{J}$ Anat Soc India. 2016;65(1):38-42.

9. Blanco MV, Vega HR, Giuliano R, Grana DR, Azzato F, Lerman $\mathrm{J}$, et al. Histomorphometry of umbilical cord blood vessels in preeclampsia. J Clin Hypertens. 2011;13(1):30-4.

10. Sontakke YA. Principles of histological techniques, immunohistochemistry and microscopy. 1st ed. India: Paras medical books pvt.ltd; 2017.

11. Koech A, Ndungu B, Gichangi P. Structural changes in umbilical vessels in pregnancy induced hypertension. Placenta. 2008;29(2):210-4.

12. Yasoob M, Bokhari ZH, Bukhari MH, Tazeen N, Khalid A. Histomorphometric study of umbilical cord in gestational hypertension and preeclampsia. Pak $\mathrm{J}$ Med Health Sci. 2014;8(3):545-9.

13. Damasceno EB, de Lima PP. Wharton's jelly absence: a possible cause of stillbirth. Autops Case Rep. 2013;3(4):43-7.

14. Almasry SM, Elfayomy AK, Hashem HE. Ultrastructure and histomorphometric analysis of human umbilical cord vessels in preeclampsia: a potential role of VEGF, VEGFR-1 and VEGFR2. Rom J Morphol Embryol. 2016;57(2):681-9.

15. Russell MJ, Dombkowski RA, Olson KR. Effects of hypoxia on vertebrate blood vessels. J Exp Zool A Ecol Genet Physiol. 2008;309(2):55-63.

16. Michiels C. Physiological and pathological responses to hypoxia. Am J Pathol. 2004;164(6):1875-82.

17. Julian RJ. The response of the heart and pulmonary arteries to hypoxia, pressure, and volume. A short review. Poult Sci. 2007;86(5):1006-11.

18. Heider A. Fetal vascular malperfusion. Arch Pathol Lab Med. 2017;141(11):1484-9.

19. Redline RW, Ravishankar S. Fetal vascular malperfusion, an update. Apmis. $2018 ; 126(7): 561-9$.

Copyright: ( $)$ the author(s), publisher. Academia Anatomica International is an Official Publication of "Society for Health Care \& Research Development". It is an open-access article distributed under the terms of the Creative Commons Attribution Non-Commercial License, which permits unrestricted non-commercial use, distribution, and reproduction in any medium, provided the original work is properly cited.

How to cite this article: Ali SA, Suma HY, Sontakke YA, Maurya DK. Histomorphometric Analysis of Umbilical Arteries in Preeclampsia. Acad. Anat. Int. 2019;5(1):40-42.

DOI: dx.doi.org/10.21276/aanat.2019.5.1.9

Source of Support: Nil, Conflict of Interest: None declared. 